\title{
Invasive Pneumococcal Disease in Refugee Children, Germany
}

\section{Stephanie Perniciaro, Matthias Imöhl, Mark van der Linden}

Refugee children in Germany are not routinely given a pneumococcal conjugate vaccine. Cases of invasive pneumococcal disease (IPD) in 21 refugee children were compared with those in 405 Germany-born children for 3 pneumococcal seasons. Refugee children had significantly higher odds of vaccine-type IPD and multidrug-resistant IPD than did Germany-born children.

$\mathrm{G}$ ermany has taken in $>1$ million refugees since 2015 (1), more than one third of whom were children $<18$ years of age (2). Invasive pneumococcal disease (IPD) is a major cause of childhood death, especially in resourcepoor environments (3). Conflict settings are associated with outbreaks of vaccine-preventable diseases for reasons ranging from poor sanitation in refugee holding areas to the rapid movement of refugees, which, in turn, allows for a similarly rapid spread of disease and the interruption of immunization services because of the lack of personnel (4).

Of the 10 most frequent countries of origin for refugees arriving in Germany in 2017 (Syria, Iraq, Afghanistan, Turkey, Iran, Nigeria, Eritrea, Russia, Somalia, and Albania), 6 have a national vaccination program that includes pneumococcal conjugate vaccines (PCVs) (5); however, because of the crisis conditions facing those who fled, timely infant vaccination is unlikely (4). Vaccine-preventable disease outbreaks have been reported in refugee housing facilities in Germany $(6,7)$, and most of these cases have originated after arrival in Germany. The vaccination program for newly arrived refugees does not include PCVs (8).

Since 1997, the German National Reference Center for Streptococci (GNRCS) has been collecting bacterial isolates from IPD cases in children occurring throughout Germany. We compared IPD isolates received from known refugee children residing in Germany to IPD isolates from Germany-born children for the 2014-15, 2015-16, and 2016-17 pneumococcal seasons.

Author affiliation: University Hospital RWTH Aachen,

Aachen, Germany

DOI: https://doi.org/10.3201/eid2410.180253

\section{The Study}

In this retrospective, unmatched case-control study, we considered all 514 isolates from children $(<16$ years of age) with IPD in the GNRCS collection isolated during July 1, 2014-June 30, 2017, for inclusion in the analysis. We defined a case of IPD as Streptococcus pneumoniae (identified by optochin sensitivity and bile solubility) isolated from a normally sterile site. For the analysis, case isolates were from refugee children with IPD, and control isolates were from Germany-born children with IPD. Refugee status was documented by GNRCS personnel in conjunction with determining vaccination status, as described elsewhere (9). Because identification of refugee status was tied to the determination of vaccination status, all children with an unknown vaccination status were excluded.

We determined serotype by using Neufeld's Quellung reaction and antimicrobial drug resistance by MIC testing, as previously described (10). Antimicrobial drug resistance was defined by the Clinical and Laboratory Standards Institute 2015 breakpoints (11).

We calculated odds ratios (ORs) and 95\% CIs with $\mathrm{R}$ software version 3.4.0 (https://www.r-project.org/foundation) using Firth's bias-reduced logistic regression and adjusted for age and sex using the logistf package (12). We assigned statistical significance to ORs for which the $95 \%$ CI did not exceed 1. Variables considered in the analysis were age, sex, vaccination status, and refugee status of the patient, as well as the serotype and antimicrobial drug resistance profile of the isolate.

During July 1, 2014-June 30, 2017, the GNRCS received 21 IPD isolates from known refugee children (Table). The average age of infection in refugee children was 3 years. Of these cases, 11 (44\%) had an unknown clinical diagnosis (6 isolates were from blood, 2 from cerebrospinal fluid, 3 from other exudates), 4 (19\%) were from meningitis, 3 $(14 \%)$ were from sepsis, and $3(14 \%)$ were from pneumonia. Thirteen refugee children, all of whom were unvaccinated, had vaccine-type IPD $(62 \%$ overall; $2014-15,67 \%$; $2015-$ $16,67 \% ; 2016-17,50 \%)$. Only 2 refugee children, both with non-vaccine-type IPD, had been vaccinated with 13 -valent PCV, both with only 1 dose, after arrival in Germany.

We determined vaccination status for 405 isolates from Germany-born children (Table). The average age at the time of infection was 2 years. Fifty-four children (13\%) had pneumonia, 88 (22\%) had sepsis, 130 (32\%) had meningitis, and 133 cases $(33 \%)$ had an unknown or other 
Table. Invasive pneumococcal disease in refugee children and German-born children, July 1, 2014-June 30, 2017*

\begin{tabular}{|c|c|c|c|c|c|c|c|}
\hline \multirow[b]{2}{*}{ IPD season } & \multirow[b]{2}{*}{ No. patients } & \multirow[b]{2}{*}{$\begin{array}{l}\text { Mean patient } \\
\text { age, } y\end{array}$} & \multicolumn{5}{|c|}{ No. (\%) patients } \\
\hline & & & Unvaccinated & $\begin{array}{c}\text { PCV13 } \\
\text { vaccinated }\end{array}$ & VT serotype & $\begin{array}{l}\text { Non-VT } \\
\text { serotype }\end{array}$ & $\begin{array}{c}\text { Resistant to } \geq 3 \text { classes } \\
\text { of antimicrobial drugs }\end{array}$ \\
\hline \multicolumn{8}{|c|}{ Refugee children in Germany } \\
\hline 2014-15 & 3 & 1 & $3(100)$ & 0 & $2(67)$ & $1(33)$ & $1(33)$ \\
\hline $2015-16$ & 12 & 3 & $10(83)$ & $2(17)$ & $8(67)$ & $4(33)$ & $4(33)$ \\
\hline $2016-17$ & 6 & 5 & $5(83)$ & 0 & $3(50)$ & $3(50)$ & $3(50)$ \\
\hline Total & 21 & 3 & $18(86)$ & $2(9)$ & $13(62)$ & $8(38)$ & $8(38)$ \\
\hline \multicolumn{8}{|c|}{ Germany-born children } \\
\hline 2014-15 & 107 & 2 & $19(18)$ & $73(68)$ & $28(26)$ & $79(74)$ & $5(5)$ \\
\hline 2015-16 & 122 & 2 & $21(17)$ & $86(70)$ & 19 (16) & $103(84)$ & $1(0.8)$ \\
\hline $2016-17$ & 176 & 3 & $45(26)$ & $117(66)$ & $28(16)$ & $148(84)$ & $4(2)$ \\
\hline Total & 405 & 2 & $85(21)$ & $276(68)$ & 75 (19) & $330(81)$ & $10(2)$ \\
\hline
\end{tabular}

diagnosis. Seventy-five cases in this group were vaccinetype IPD (19\% overall; 2014-15, 26\%; 2015-16, 16\%; 2016-17, 16\%). Refugee children had significantly higher odds of contracting vaccine-type IPD (OR 6.60, 95\% CI 2.73-16.84) over the study period.

Eight isolates (38\% overall; 2014-15, 33\%; 2015-16, $33 \%$; 2016-17, 50\%) from refugee children were resistant to $\geq 3$ classes of antimicrobial drugs, compared with 10 isolates (2\% overall; 2014-15, 4\%; 2015-16, 1\%; 2016-17, $2 \%$ ) from Germany-born children. Refugee children had significantly higher odds (OR 23.84, 95\% CI 7.98-72.73) of contracting antimicrobial-resistant IPD over the study period. Five vaccine-type isolates (38\% overall; 2014-15, $50 \%$; 2015-16, 25\%; 2016-17, 67\%) from refugees were resistant to $\geq 3$ of antimicrobial drugs, compared with 5 vaccine-type isolates (7\% overall; 2014-15, 11\%; 2015-16, 5\%; 2016-17, 4\%) from Germany-born children. Among vaccine-type IPD cases, refugee children were significantly more likely (OR 8.82, 95\% CI 2.13-40.10) to have antimicrobial drug-resistant infections.

IPD incidence estimates are shown in online Technical Appendix Table 1 (https:/wwwnc.cdc.gov/EID/ article/24/10/18-0253-Techapp1.pdf). For single-season ORs, the CIs were often wide, and the sample sizes in refugee children were low (2014-15, $\mathrm{n}=3$; 2015-16, $\mathrm{n}=12$; 2016-17, $\mathrm{n}=6$ ). These ORs are shown in online Technical Appendix Table 2 and should be interpreted cautiously.

\section{Conclusions}

Refugee children in Germany are at greater risk of contracting vaccine-type IPD, antimicrobial drug-resistant IPD, and antibiotic-resistant vaccine-type IPD. As such, a PCV program for refugee children may be worth considering in Germany. Vaccination in newly arrived refugees presents an opportunity to cost-effectively, safely, and humanely protect a vulnerable population from negative health outcomes resulting from vaccine-preventable diseases (13). Given that children in Germany with insecure residence status are twice as likely to be incompletely vaccinated (2), a PCV program for refugee children in Germany might require additional follow-up measures to ensure consistency and provide sufficient protection, particularly because PCV dosing in Germany-born children with IPD has been lax (9). A PCV program could help reduce antimicrobial drugresistant pneumococcal infections, the carriage of resistant strains (14), overall antimicrobial drug use, and the prevalence of resistance genes within the pneumococcal population (15).

The IPD case numbers from refugees are low, but the proportion of vaccine-type isolates and antimicrobial drug-resistant isolates from refugee children are nevertheless much higher than those of Germany-born children. Children of unknown vaccination status $(n=109)$ were excluded from the analysis; because of the small sample sizes, if even 1 additional child with vaccine-type IPD per year was a refugee, the effects we describe would be magnified (online Technical Appendix Table 3).

The risk of vaccine-type IPD is low among fully vaccinated children in Germany. However, among unvaccinated and undervaccinated children, a reintroduction of vaccine-type pneumococci may result in increased risk of pneumococcal disease. Without intervention, refugee children may continue to constitute a special risk group for vaccine-type IPD and antimicrobial drug-resistant IPD in Germany. Fully immunizing these children against vaccine-type IPDs may help reduce the risk for IPD illness and death in Germany.

\section{About the Author}

Mrs. Perniciaro is a doctoral candidate at the German National Reference Center for Streptococci, University Hospital RWTH Aachen. Her interests include invasive pneumococcal disease epidemiology and pneumococcal conjugate vaccine effectiveness.

\section{References}

1. Razum OS, Saß A-C, Bozorgmehr K. Gesundheitliche Versorgung von Geflüchteten: Herausforderungen und Lösungsansätze. Bundesgesundheitsblatt. 2016;59:543-4. http://dx.doi.org/10.1007/s00103-016-2344-5 
2. Wenner J, Razum O, Schenk L, Ellert U, Bozorgmehr K. Gesundheit von Kindern und Jugendlichen aus Familien mit ungesichertem Aufenthaltsstatus im Vergleich zu Kindern mit und ohne Migrationshintergrund: Auswertung der KiGGSDaten 2003-06. Bundesgesundheitsblatt. 2016;59:627-35. http://dx.doi.org/10.1007/s00103-016-2338-3

3. O'Brien KL, Wolfson LJ, Watt JP, Henkle E, Deloria-Knoll M, McCall N, et al.; Hib and Pneumococcal Global Burden of Disease Study Team. Burden of disease caused by Streptococcus pneumoniae in children younger than 5 years: global estimates. Lancet. 2009;374:893-902. http://dx.doi.org/10.1016/ S0140-6736(09)61204-6

4. Nnadi CE, Etsano A, Uba B, Ohuabunwo C, Melton M, wa Nganda G, et al. Approaches to vaccination among populations in areas of conflict. J Infect Dis. 2017;216(S1):368-72. http://dx.doi.org/10.1093/infdis/jix175

5. World Health Organization. WHO vaccine-preventable diseases: monitoring system. 2017 global summary [cited 2017 Sept 20] http://apps.who.int/immunization_monitoring/globalsummary/ schedules

6. Grote U, Schleenvoigt BT, Happle C, Dopfer C, Wetzke M, Ahrenstorf G, et al. Norovirus outbreaks in German refugee camps in 2015. Z Gastroenterol. 2017;55:997-1003. http://dx.doi.org/10.1055/s-0043-109701

7. Kühne AG, Gilsdorf A. Ausbrüche von Infektionskrankheiten in Gemeinschaftsunterkünften für Asylsuchende 2004-2014 in Deutschland. Bundesgesundheitsblatt. 2016;59:570-7. http://dx.doi.org/10.1007/s00103-016-2332-9

8. Robert Koch Institut. Konzept zur Umsetzung frühzeitiger Impfungen bei Asylsuchenden nach Ankunft in Deutschland. Epidemiologisches Bulletin. 2015;41:439-48. http://dx.doi.org/ 10.17886/EpiBull-2015-011.4

9. van der Linden M, Falkenhorst G, Perniciaro S, Fitzner C, Imöhl M. Effectiveness of pneumococcal conjugate vaccines (PCV7 and PCV13) against invasive pneumococcal disease among children under two years of age in Germany. PLoS One. 2016;11:e0161257. http://dx.doi.org/10.1371/journal.pone.0161257

10. Imöhl M, Reinert RR, van der Linden M. Antibiotic susceptibility rates of invasive pneumococci before and after the introduction of pneumococcal conjugate vaccination in Germany. Int J Med Microbiol. 2015;305:776-83. http://dx.doi.org/10.1016/ j.ijmm.2015.08.031

11. Clinical and Laboratory Standards Institute. Performance standards for antimicrobial susceptibility testing: twenty-fifth informational supplement (M100-S25). Wayne (PA):

The Institute; 2015.

12. Heinze G. A comparative investigation of methods for logistic regression with separated or nearly separated data. Stat Med. 2006;25:4216-26. http://dx.doi.org/10.1002/sim.2687

13. Pavlopoulou IDT, Tanaka M, Dikaloti S, Samoli E, Nisianakis P, Boleti OD, et al. Clinical and laboratory evaluation of new immigrant and refugee children arriving in Greece. BMC Pediatr. 2017;17:132. http://dx.doi.org/10.1186/s12887-017-0888-7

14. Hampton LM, Farley MM, Schaffner W, Thomas A, Reingold A, Harrison LH, et al. Prevention of antibiotic-nonsusceptible Streptococcus pneumoniae with conjugate vaccines. J Infect Dis. 2012;205:401-11. http://dx.doi.org/10.1093/infdis/jir755

15. Grijalva CG. Decrease in antibiotic use, an added benefit of PCVs. Lancet Infect Dis. 2014;14:175-7. http://dx.doi.org/10.1016/ S1473-3099(13)70356-6

Address for correspondence: Stephanie Perniciaro, German National Reference Center for Streptococci, Department of Medical Microbiology, RWTH Aachen University Hospital, Pauwelsstraße 30, 52074 Aachen Germany; email: sperniciaro@ukaachen.de

\section{EID Podcast:}

Visions of Matchstick Men and Icons of Industrialization

Byron Breedlove, managing editor of the journal, discusses and reads his November 2017 cover art essay. This cover (Going to Work, 1943) is by English artist Laurence Stephen Lowry (1887-1976) who died of pneumonia in 1976.

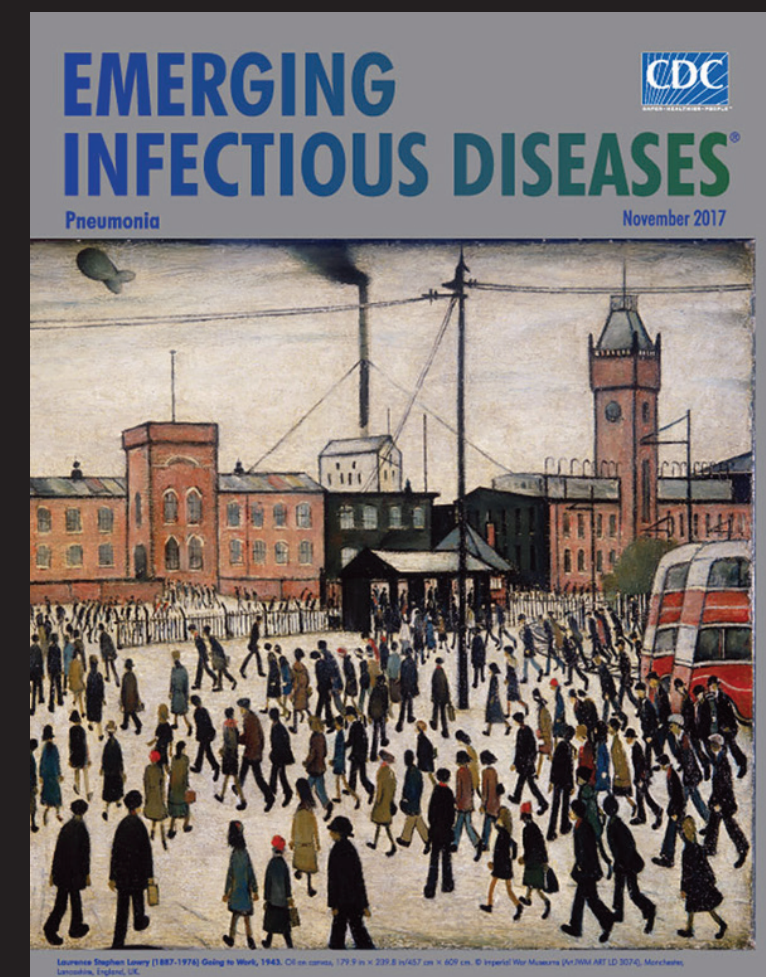

Visit our website to listen: https://www2c.cdc.gov/ podcasts/player.asp?f $=\mathbf{8 6 4 7 1 7 3}$ EMERCING INFECTIOUS DISEASES 